\title{
Economics and governance for sustainability
}

LOUIS MEULEMAN, Ph.D.

INGEBORG NIESTROY, Ph.D.

Guest editors' introduction

https://doi.org/10.3326/pse.43.4.1

Louis MEULEMAN

Public Governance Institute, University of Leuven, Parkstraat 45 - B-3000 Leuven, Belgium

e-mail: louismeuleman@ps4sd.eu

ORCiD: https://orcid.org/0000-0001-8171-2525

Ingeborg NIESTROY

Institute of Advanced Sustainability Studies (IASS), Berliner Str. 130, 14467 Potsdam, Germany

e-mail: inge.niestroy@ps4sd.eu

ORCiD: https://orcid.org/0000-0003-1063-4536 
Sustainable development is a concept and a broad umbrella of goals, policies and policy tools with which to address the key challenges of our time in a coherent, holistic way. It is about balancing the environmental, social and economic dimensions of our societies: planet, people and prosperity. The United Nations 2030 Agenda with its seventeen Sustainable Development Goals (SDGs) is conceived as a "meta-policy" to guide decisions of governments, business and civil society in all 193 UN member states.

Implementation of the SDGs is all about governance. It is about how the goals are achieved, considering how countries differ in terms of political and administrative traditions, values and mind-sets. Such a meta-policy deserves meta-governance: it requires the taking of a birds'-eye perspective on the different governance styles - usually characterised as hierarchical, network and market governance - and their combinations (Meuleman, 2018).

In each of the main three dimensions of sustainable development (environment, social, economic) there are debates about the "best" approach to the achievement of sustainability. Environmentalists may prefer hierarchical tools such as laws and standards; social scientists may seek solutions in the "network society", while economists tend to favour market mechanisms and see the degree of government intervention as a key variable.

Economic theory and practice applied to sustainable development is currently a dynamic area, with a range of - typically conflicting - beliefs, theories and practices. At the same time, a "green" or sustainable economy is becoming a political and economic reality. Frictions between theory and practice, and among different schools of thinking are becoming more visible: no longer can academic economists "hide" within their own schools.

It is therefore time to take stock: what are currently the most salient developments in theory and practice? How can we interpret the long-standing discussions on growth and how to measure it "beyond GDP", which go back at least fifty years? In the summary of US Senator Robert F. Kennedy at the University of Kansas on March 18, 1968 "Gross National Product counts air pollution and cigarette advertising, and ambulances to clear our highways of carnage. It counts special locks for our doors and the jails for the people who break them. It counts the destruction of the redwood and the loss of our natural wonder in chaotic sprawl. (...) Yet the gross national product does not allow for the health of our children, the quality of their education or the joy of their play. (...) It measures neither our wit nor our courage, neither our wisdom nor our learning, neither our compassion nor our devotion to our country, it measures everything in short, except that which makes life worthwhile". ${ }^{1}$

\footnotetext{
${ }^{1}$ https://www.theguardian.com/news/datablog/2012/may/24/robert-kennedy-gdp
} 
Which revisions of economic systems do we need for the 21 st century considering "the growth of (planetary) limits" and the need to serve sustainability? What are the debates, opportunities and obstacles in the increasingly popular approaches to sustainable finance and sustainable budgeting? And what about access to financial services and institutions? What new thinking appears to deliver practicable guidance for public sector economics, in various contexts?

In this special issue of Public Sector Economics we present some theoretical, empirical and policy-oriented contributions analysing the state of play of economic theory and practice of sustainable development, with a view to its contributing to the governance of the SDGs. Although it does not cover all the discussions, the articles in the issue do provide very relevant contributions to the debate.

\section{TEACHING THE SILOS TO DANCE?}

When we look at the media and politics, natural sciences dominate the perspective. They provide facts and projections about climate change, depletion of natural resources, and about the impacts of economic and social life on the physical world in which we live. They can inform us about limits, tipping points and preconditions, and can provide technical solutions and opportunities. Social sciences deal with human behaviour and can provide ideas about how technical solutions might be implemented. Natural and social sciences operate in quite strict silos and lack a common understanding. The economic discipline is a basket of silos on its own, rather separated from the other social sciences. In a time where climate change is a crucial but not the only huge challenge people around the world are facing, one would hope that the academic silos would learn to communicate with each other - or as we have framed it earlier, would be taught to 'dance' (Niestroy and Meuleman, 2016). One step beyond that is to incorporate non-academic knowledge: moving from inter- via multi- to trans-disciplinary research (see e.g. Bunders et al., 2010). The articles in this issue are transdisciplinary in the sense that they refer to both 'white' (academic, peer-reviewed) and 'grey' literature sources (e.g. governmental or other non-academic publications) and consider them both relevant.

\section{FROM BARRIERS TO OPPORTUNITIES}

Resource efficiency, a key dimension of the transition to the circular economy, is a good example of an economic concept that is integrated in a joint green economy policy framework. Florian Flachenecker and Jun Rentschler provide evidence on the complex incentives, trade-offs, and challenges associated with the economics and politics of resource efficiency investments, especially in light of the SDGs and the Paris Climate Agreement, which were both adopted in 2015. They examine the role of resource efficiency in reconciling environmental and economic objectives, making particular reference to the investment barriers and transitional implications of moving economies towards more circular and resource efficient pathways. They provide a policy-oriented guide and toolbox to help overcome barriers, unlock the economic potential of resource efficiency, and highlight the challenges associated with resource transition. They also highlight 
the crucial role that can play, especially in developing and emerging economies and in multilateral development, in resolving information barriers, facilitating technology transfer, mitigating financing constraints, and thus encouraging first movers. Governments are crucial actors but need financial institutions to accelerate policy implementation.

\section{WINNERS AND LOSERS - AND HOW TO COMPENSATE FOR LOSSES}

In many countries there is political willingness to engage with sustainability transitions, with dedicated governance frameworks to guide the processes of change. In the communication around these transitions we tend to showcase the winners of the transition. Most governance literature points at mutual gains negotiation methods to prevent the emergence of losers and create 'win-win' package deals. In his article, David Horan presents a different - and less researched - approach, namely (economic) compensation strategies. Drawing on the political economy literature of reform in transition economies, he proposes three compensation strategies to buy out or weaken the opposition of strategic losers to the implementation of new governance frameworks for SDG transformation: big bang, optimal sequencing and divide-and-rule governance reforms. This can help to frame discussions around the political feasibility of new governance frameworks for SDG transformations. The author suggests that careful consideration needs to be given to the design of these compensation packages, since history tells us that buying acceptance for reform can involve not just variation in economic outcomes, it can also have long-term political implications and distributional effects.

\section{SUSTAINABILITY AND THE DISBALANCE BETWEEN EFFICIENCY AND SUFFICIENCY}

Rudi Kurz criticises the current political focus on eco-efficiency because it brings about rebound effects that can annihilate the positive effects. He advocates a new balance between eco-efficiency and sufficiency. He argues that all strategies for sustainable development follow the two basic options of efficiency and sufficiency. Eco-efficiency (less environmental impact per unit of GDP) still plays the most important role and has the potential to delink economic growth and environmental impacts. Growth could continue (green growth). However, no efficiency revolution has materialized yet; one reason is rebound effects. Therefore, more emphasis on the sufficiency option is necessary, restricting the volume of output. Consumption patterns and lifestyles have to change, economic growth has to end. There are much more significant consequences for the transformation of economies and societies than those of the "conventional" efficiency option. Governments have to end growth policies and replace them by sufficiency policies. Only with policy concepts that integrate efficiency and sufficiency components is there a chance of fulfilling the environmental SDGs - which are fundamental to many other SDGs.

\section{SDG BUDGETING}

Elisabeth Hege, Laura Brimont and Félicien Pagnon explore the use and added value of integrating the SDGs and indicators in budgeting processes. Several 
countries have announced in their Voluntary National Reporting (VNRs) at the UN their intention to use the SDGs in their budgetary processes, but few have specified why it would be relevant to do so, or how it could be operationalized. Based on nine case studies conducted through interviews, it was found that SDG budgeting is still in its infancy. Nevertheless, four ways could be identified in which countries are starting to integrate the SDGs into budgeting processes. Most of the studied countries either map their budgets against the SDGs or include qualitative reporting in their main budget document. Less often, countries use the SDGs to improve their budget performance evaluation system, or use them as a management tool for resource allocation. Most of the countries follow a technical approach. Only rarely are the SDGs used politically or referenced in the budgetary debate.

\section{INNOVATION FOR FINANCIAL INCLUSION}

Luigi Ferrata analyzes the relation between the UN Agenda 2030 and finance. Although none of the goals of that Agenda is dedicated to finance, can the use of financial instruments play a role in achieving some of the SDGs? Can financial instruments contribute to the reduction of hunger and poverty, to ensuring healthy lives, gender equality, decent jobs and growth of micro, small and medium-sized enterprises (MSMEs), reducing inequalities, enhancing the fight against corruption and increasing the mobilization of additional financial resources? This article highlights how financial inclusion, i.e. the access to financial services, allows the economically weakest to contribute to the achievement of the SDGs and to improve their life conditions. Evidence from the UNSGSA (2018) report on integrating SDG progress through digital financial inclusion shows that digital finance is the key, which can help in boosting financial inclusion.

Decision-makers have to implement measures to speed up digital financial inclusion like creating effective consumers' protection systems, reducing physical and technological barriers, increasing the financial knowledge of the less educated and developing reliable and secure technical infrastructures. Financial operators have to learn more about potential users like women, farmers and small entrepreneurs in order to propose products and services based on their real needs.

\section{FISCAL AND FINANCIAL REFORM FOR SUSTAINABILITY}

\section{IN THE ARAB REGION}

In the last article of this issue, several governance and financial challenges of the implementation of the SDGs come together in a critical study of the political and institutional coherence, compatibility, and contextualisation of Agenda 2030 in the Arab region. Lamia Moubayed Bissat and Carl Rihan address the deficiencies in the contextualization of the Agenda for the Arab region and link them to the specific context. Drawing on recent research, the authors argue that the region's political and institutional context is one of peacebuilding and resilience-building and propose a corresponding SDGs implementation framework. Drawing on the Addis Ababa Action Areas, the article then explores the capacity of the region to address such priorities by studying the financing aspect of policymaking. Arguing 
that domestic resources mobilization, the most potent means of policy implementation, is crippled by two underlying factors, political exclusiveness and institutional inefficiency, the authors conclude with a "roadmap" for improvements in the contextualization of Agenda 2030 by focusing on fiscal and financial reform and on the curbing of illicit financial flows on one hand, and de-escalation and institutional peacebuilding on the other.

\section{CONCLUSIONS}

From a public governance point of view, one of the most interesting insights that can be drawn from the collection of articles in this issue is that taking the perspective of economics can bring about analyses and recommendations that are traditionally neglected by those who study the processes of policy making and policy implementation (i.e. political science). This shows, again, the need for social scientists to work closer together across academic disciplines.

A second conclusion is that the findings presented in the articles in this issue support the assumption that context matters - not only in sustainability governance but also in economic governance. There are no one-size-fits-all solutions. Each country must follow its own path, building on its own governance structures, political, economic and social realities, local strengths and unique needs, while reforms that consider meta-governance, i.e., governance of different governance styles, are important as they are more likely to be contextual (CEPA, 2019). The consequence of this is that analysis of the (national, local) governance context (see e.g. Niestroy et al., 2019 for the institutional context of SDG implementation in EU countries) is a precondition for effective governance.

Ultimately, we are pleased that we have tried to connect the silos of public governance and economics in a special issue of this Journal. We hope that the six articles will increase the appetite for such cross-fertilization. 


\section{REFERENCES}

1. Bunders J. F. [et al.], 2010. How can transdisciplinary research contribute to knowledge democracy? In: R. Veld, ed. Knowledge Democracy. Berlin; Heidelberg: Springer. https://doi.org/10.1007/978-3-642-11381-9_11

2. CEPA, 2019. Governance and public administration aspects of empowering people and ensuring inclusiveness and equality. Contribution by the Committee of Experts on Public Administration to the 2019 thematic review of the High-level Political Forum on Sustainable Development.

3. Meuleman, L., 2018. Metagovernance and Sustainability: A Framework for Implementing the SDGs. London: Routledge.

4. Niestroy, I. [et al.], 2019. Europe's approach to implementing the Sustainable Development Goals: Good practices and the way forward. Policy Department for External Relations Directorate General for External Policies of the Union, PE 603.473 - February 2019.

5. Niestroy, I. and Meuleman, L., 2016. Teaching Silos to Dance: A Condition to Implement the SDGs. Guest article published on 21 July 2016.

6. UNSGSA, 2018a. Igniting SDG progress through digital financial inclusion. United Nations Secretary-General's Special Advocate for Inclusive Financial Development. 